\title{
Study on neural tube defects of neonates and folic acid awareness at a Teaching Hospital in Sri Lanka
}

\author{
N N Dissanayake ${ }^{1}$, S C Wickramasinghe ${ }^{2}$, D M W H Bandara ${ }^{3}$
}

Sri Lanka Journal of Child Health, 2010; 39:11-16

(Key words: Neural tube defects, NTDs, folic acid, awareness of folic acid)

\begin{abstract}
Objectives: To assess awareness and knowledge of folic acid (FA), educate about importance of using of pre-conceptional FA, find out the common source of information about FA and identify some epidemiological characteristics of neural tube defects (NTDs)
\end{abstract}

\section{Setting: Teaching Hospital, Kandy}

Method: A case control study was carried out for 17 months from July 2002 of all newborns with NTDs delivered at General Hospital (GH) Kandy and newborns with NTDs transferred from other hospitals. An age and sex matched group of babies born at GH Kandy with no obvious abnormalities was selected as the control. To increase statistical confidence we took 3 controls for 1 case. A pretested questionnaire was administered to obtain data. While interviewing, we counselled all mothers about value of pre-conceptional FA usage.

Results: During the study period 14,580 live births took place at GH Kandy and twenty of them had NTDs. The number of babies with NTDs transferred from other hospitals was 30. The control group comprised 150 mothers with normal babies. Fourteen (28\%) of the affected group were able to identify folic acid tablet as a vitamin taken during pregnancy, in comparison to $87(58 \%)$ of the control group. One $(2 \%)$ from the affected group and $70(46 \%)$ from the control group knew about the value of pre-conceptional FA. None of the affected mothers had used FA preconceptionally whereas $20(13 \%)$ of the control group had used it. Four (8\%) of the affected mothers identified preventing birth defects as the primary reason to take FA whereas $54(26 \%)$ of the control group mothers believed that folic acid helped in preventing birth defects. Awareness of FA usage came mainly from midwives.

\footnotetext{
${ }^{1}$ Paediatric Registrar, ${ }^{2}$ Consultant Paediatrician, ${ }^{3}$ Neonatal Medical Officer, Teaching Hospital Kandy
}

(Received 20 March 2009. Accepted 22 May 2009)
Conclusions: Knowledge and use of FA in relation to pregnancy were grossly inadequate especially among mothers who had affected babies.

\section{Introduction}

Neural Tube Defects (NTDs) are the second most prevalent group of congenital anomalies in the world, second only to cardiac malformations and are associated with substantial morbidity \& mortality ${ }^{1,2}$. NTDs are congenital malformations occurring during early intrauterine life around 3-4 weeks of gestation by failure of closure of the neural tube which eventually forms the central nervous system.

Annually worldwide an estimated 300,000 or more babies are born with spine bifida and anencephaly. In the United States reported birth prevalence rates vary from 4 to 10 per 10,000 live births ${ }^{4}$. Some studies in countries such as Ireland, United Kingdom, China, Hungary, Mexico and India (3.99 per1000) have reported higher rates. Occasionally rates as high as $1 \%$ have been reported ${ }^{5}$.

Many studies have now conclusively proved the beneficial effects of FA supplementation in preventing NTDs. The United Kingdom Medical Research Council conducted a double blind placebo control trial ${ }^{6}$ which showed FA to have a $72 \%$ protective effect. Similar benefits were also demonstrated in a trial conducted in India $(60 \%$ reduction in occurrence of NTDs $)^{7}$. Evidence from international randomized controlled trials showed that daily maternal use of folate prior to and during early pregnancy reduced both recurrence as well as first occurrence of NTDs ${ }^{8,9}$. No information is available in Central province of Sri Lanka on this matter.

\section{Objectives}

1. To assess the awareness and knowledge of folic acid among the study population.

2. To educate the study population regarding the importance of usage of peri-conceptional folic acid. 
3. To find out the common source of information about folic acid in the mothers studied.

4. To identify some epidemiological characteristics of NTDs when compared to normal pregnancies.

\section{Method}

This prospective case-control study was conducted at Teaching Hospital Kandy over 17 months from $1^{\text {st }}$ July 2002. Study population comprised all newborn babies with NTDs delivered at TH Kandy and newborns with NTDs transferred from other hospitals during period of study. Age and sex matched babies born at TH Kandy in the same period with no obvious abnormalities were taken as the control group. Since this was a case-control study, in order to increase the statistical confidence, we took 3 controls per index case.

The study was approved by the Ethical Review Committee, TH Kandy. After obtaining verbal consent, a pre-tested questionnaire was filled. All participants were interviewed by the first author or the third author and we counselled all mothers regarding value of pre-conceptional FA use.

\section{Results}

Total number of live birth during the study period was 14,580 . Number of babies born with NTD at T.H.Kandy was 20. Thirty newborns with neural tube defects were transferred from other hospitals. Control group count was 150 .

\section{Knowledge of folic acid}

\section{a) Identification as a vitamin}

As shown in table 1, among the affected group only $14(28 \%)$ mothers were able to identify FA as a vitamin taken during pregnancy, whereas $87(58 \%)$ of the control group mothers were able to identify FA as a vitamin. The difference between two groups was significant with a $\mathrm{P}$ value of $<0.001$.

Table 1

Identification of folic acid as a vitamin

\begin{tabular}{|l|c|c|}
\hline \multicolumn{1}{|c|}{ Groups } & Identified & Not identified \\
\hline $\begin{array}{l}\text { Affected Group } \\
(\mathrm{n}=50)\end{array}$ & $14(28 \%)$ & $36(72 \%)$ \\
\hline $\begin{array}{l}\text { Control Group } \\
(\mathrm{n}=150)\end{array}$ & $87(58 \%)$ & $63(42 \%)$ \\
\hline
\end{tabular}

b) Value of pre-conceptional folic acid usage

As shown in table 2 only 1 out of $50(2 \%)$ affected mothers knew about the value of pre-conceptional FA use. However, 70 of $150(46 \%)$ control group mothers were aware of the importance of FA usage.
Table 2

Value of pre-conceptional folic acid usage

\begin{tabular}{|l|c|c|}
\hline \multicolumn{1}{|c|}{ Groups } & Aware & Unaware \\
\hline $\begin{array}{l}\text { Affected Group } \\
(\mathrm{n}=50)\end{array}$ & $01(02 \%)$ & $49(98 \%)$ \\
\hline $\begin{array}{l}\text { Control Group } \\
(\mathrm{n}=150)\end{array}$ & $70(46 \%)$ & $80(54 \%)$ \\
\hline
\end{tabular}

c) Average knowledge of $F A$

We attempted to determine the association women make between folic acid consumption and the prevention of birth defects. Thus our questionnaire included three components viz. FA prevents birth defect/ unknown / other. Breakdown of response given as reason for taking folic acid is shown in table 3 .

Table 3

Average knowledge of folic acid

\begin{tabular}{|l|c|c|c|}
\hline \multicolumn{1}{|c|}{ Groups } & Unknown & $\begin{array}{c}\text { Birth } \\
\text { Defects }\end{array}$ & Other \\
\hline $\begin{array}{l}\text { Affected Group } \\
(\mathrm{n}=50)\end{array}$ & $39(78 \%)$ & $04(08 \%)$ & $07(14 \%)$ \\
\hline $\begin{array}{l}\text { Control Group } \\
(\mathrm{n}=150)\end{array}$ & $69(46 \%)$ & $39(26 \%)$ & $42(28 \%)$ \\
\hline
\end{tabular}

Only $4(8 \%)$ affected mothers identified preventing birth defects as the primary reason to take folic acid, whereas $39(26 \%)$ control group mothers believed folic acid prevents birth defects.

\section{Common source of information about folic acid}

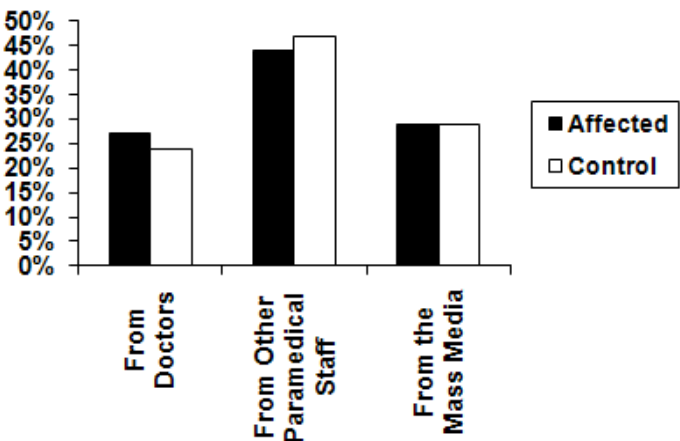

Figure 1: Common source of information about folic acid

As depicted in the bar chart (Figure 1) both affected and control group mothers obtained information about FA from other medical staff mainly public health workers. Among the affected group 22 (44\%) mothers knew about FA through public health workers; doctors contributed only $27 \%$ while information through mass media was $29 \%$. Among the control group information was obtained through public health workers in $84(47 \%)$ whereas doctors \& mass media contributed $24 \%$ and $29 \%$ respectively. 
3. Pre-conceptional folic acid usage

None of the affected mothers had taken preconceptional FA whereas $20(13 \%)$ control group mothers had taken FA pre-conceptionally. However, $130(87 \%)$ of the control group had not taken FA preconceptionally. These are shown in table 4 .

Table 4

Pre-conceptional folic acid usage

\begin{tabular}{|l|c|c|}
\hline \multicolumn{1}{|c|}{ Groups } & Used & Not used \\
\hline Affected Group $(\mathrm{n}=50)$ & $00(00 \%)$ & $50(100 \%)$ \\
\hline Control Group $(\mathrm{n}=150)$ & $20(13 \%)$ & $130(87 \%)$ \\
\hline
\end{tabular}

\section{Post-conceptional folic acid usage}

Post-conceptional folic acid usage was assessed according to the trimesters (figure 2). In the first trimester only $1(2 \%)$ of the affected group had taken FA compared to $22(15 \%)$ in the control group. In second trimester more than two thirds of mothers in both affected and control group took folic acid (79\% \& 83\% respectively). Three (6\%) of the affected group and 1 mother $(2 \%)$ in the control group had never taken FA throughout the pregnancy.

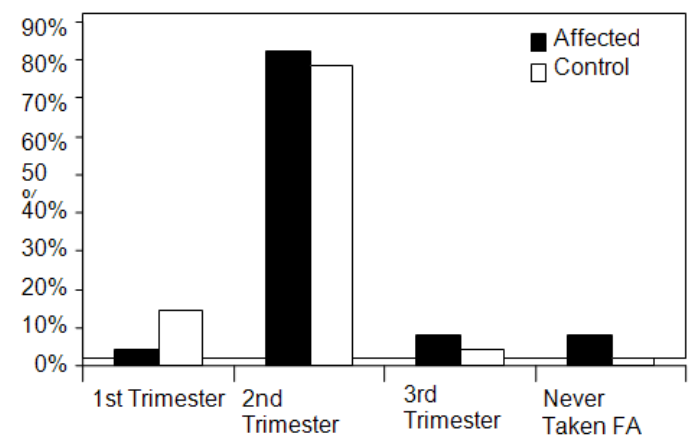

Figure 2: Post-conceptional folic acid usage

\section{Frequency of folic acid use}

We interviewed our study group regarding frequency of FA use on the basis of daily intake/ less than daily. This is shown in table 5.

Table 5

Frequency of folic acid use

\begin{tabular}{|l|c|c|c|c|c|c|}
\hline & \multicolumn{2}{|c|}{$<\mathbf{2 0}$ Years } & \multicolumn{2}{c|}{$\mathbf{2 0}-\mathbf{3 5}$ Years } & \multicolumn{2}{c|}{$>\mathbf{3 5}$ Years } \\
\hline \multirow{2}{*}{ Affected $(\mathrm{n}=47)$} & Daily & $<$ Daily & Daily & $<$ Daily & Daily & $<$ Daily \\
\cline { 2 - 7 } & 03 & 01 & 33 & 07 & 02 & 01 \\
\hline Control $(\mathrm{n}=149)$ & 16 & 04 & 99 & 21 & 06 & 03 \\
\hline
\end{tabular}

Of the women who took folic acid supplement post-conceptionally, overall more than two thirds took FA daily both in the affected group and the control group.

\section{Consumption of green leaves}

All mothers (both affected and control) reported consumption of green leaves frequently. We considered "frequently" as five or more times per week taking at least one meal containing green leaves. However, the majority cooked the leaves before consumption.

7. Odds ratio $(\mathrm{ad} / \mathrm{bc})$ of 3.6 revealed an increase risk of NTD following consanguineous marriage. This is shown in table 6 .

Table 6

NTDs following consanguineous marriage

\begin{tabular}{|l|l|l|}
\hline & $\begin{array}{l}\text { Affected } \\
(\mathbf{n = 5 0 )}\end{array}$ & $\begin{array}{l}\text { Control } \\
(\mathbf{n}=\mathbf{1 5 0})\end{array}$ \\
\hline Consanguineous & $15(\mathrm{a})$ & $16(\mathrm{~b})$ \\
\hline Non- consanguineous & $35(\mathrm{c})$ & $134(\mathrm{~d})$ \\
\hline
\end{tabular}

8. Three $(6 \%)$ of the affected group had a positive family history of NTD whereas the control group had none.
9. Among the affected group 35 males and 15 females had NTD, so that male to female ratio was 2.3:1

\section{Birth order}

This is shown in table 7

Table 7

Birth order

\begin{tabular}{|c|c|}
\hline Parity & Number \\
\hline P 1 & 26 \\
\hline P 2 & 16 \\
\hline P 3 & 04 \\
\hline P 4 & 01 \\
\hline P 5 & 03 \\
\hline
\end{tabular}

According to the table most affected babies (26 of 50) were first born.

\section{Parental age at time of birth of newborn} with NTD

This is shown in table 8 . Majority $(80 \%)$ of parents were between 20-35 years of age when the affected babies were born.

Table 8

Parental age at time of birth of newborn with NTD

\begin{tabular}{|c|c|c|c|}
\hline & $<\mathbf{2 0}$ years & $\mathbf{2 0}-\mathbf{3 0}$ years & $>\mathbf{3 5}$ years \\
\hline Father & $01(2 \%)$ & $40(80 \%)$ & $09(18 \%)$ \\
\hline Mother & $07(15 \%)$ & $40(80 \%)$ & $03(5 \%)$ \\
\hline
\end{tabular}




\section{Types of NTD}

This is shown in table 9.

Table 9

Types of NTD

\begin{tabular}{|l|c|}
\hline \multicolumn{1}{|c|}{ Type } & Affected number \\
\hline Meningomyelocoele & 30 \\
\hline Meningocoele & 07 \\
\hline Encephalocoele & 06 \\
\hline Other & 07 \\
\hline
\end{tabular}

Two thirds ( 30 of 50 ) of the affected babies had meningomyelocoeles.

\section{Social Class}

Definition

I Professionals

II Managers, technicians etc

III Skilled

IV Partial skilled

V Unskilled

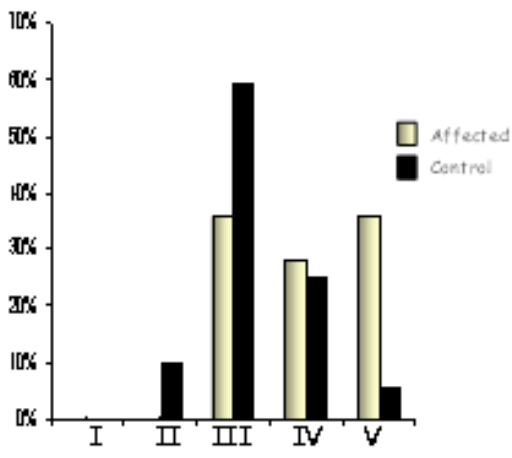

Figure 3: Social Class

We categorized our study group into 5 social classes according to their occupation. As shown in the bar chart most of the mothers were from social class III. None of the study population categorized as social class I and only $10 \%$ of the control group was from social class II. Nineteen $(38 \%)$ of the affected group mothers were from social class-V.

\section{Residential area}

This is shown in table 10 .

Table 10

Residential area

\begin{tabular}{|c|c|c|}
\hline $\begin{array}{c}\text { Residential } \\
\text { Area }\end{array}$ & $\begin{array}{c}\text { Affected } \\
(\mathbf{n}=\mathbf{5 0})\end{array}$ & $\begin{array}{c}\text { Control } \\
(\mathbf{n}=\mathbf{1 5 0})\end{array}$ \\
\hline Estate & $18(36 \%)$ & $07(5 \%)$ \\
\hline Urban & $22(44 \%)$ & $121(80 \%)$ \\
\hline Rural & $10(20 \%)$ & $22(15 \%)$ \\
\hline
\end{tabular}

Among the affected mothers $18(36 \%)$ were from estate sector whereas only $7(5 \%)$ were from estate sector in the control group.

\section{Discussion}

Knowledge and awareness of FA in relation to pregnancy was grossly inadequate in the affected group. Both in the control and the affected group most did not know that folic acid helps to prevent birth defects. When compared to studies done worldwide, the situation is almost the same. A survey carried out in 1999 in USA showed only $47 \%$ of women took FA supplement in spite of all the health promotions and only $37 \%$ were aware of the value of $\mathrm{FA}^{10}$. In Australia, many women (up to $70 \%$ ) were unaware of FA \& many women (up to $70 \%$ ) did not take FA supplements preconceptionally ${ }^{11,12}$.

Family health workers contributed to $44 \%$ in the affected group and $47 \%$ in the control group with regards to supplying the information about FA. As our study was a case control study this type of question relies on mothers' long term memory and so the results may not be totally reliable.

With regards to frequency of FA usage in postconceptional period majority of mothers in all the age groups took FA daily. These results are reassuring since it indicates that if mothers were more aware of value of pre-conceptional FA, a rise in pre-conceptional FA usage could be expected.

According to our study prevalence of NTDs in the TH Kandy was $0.14 \%$. This may not be the true prevalence because we did not include the still births \& spontaneous miscarriages during the study period. When compared to studies done worldwide, several studies have reported that the prevalence rate differs from country to country. In England ${ }^{13}$ the prevalence was $0.2 \%$ (2:1000), in USA \& East to West Canada $2.5-3.5$ per $1000^{14}$, and in Northern China 4.8: 1000 pregnancies $^{15}$.

Male to female ratio according to our study was 2.3:1 indicating NTD is commoner in boys than girls. However, when compared to long term studies done worldwide the sex ratio is different from our study. Anencephaly and spina bifida seem to occur more often among females ${ }^{16}$. This difference may be due to short duration of our study and small number of the study population.

We observed that the consanguineous marriages increase the risk of NTDs in our study. Studies done in USA suggest that the recurrence risk for first-degree relatives of affected mothers is approximately 1 in 30 . For second-degree relatives the risk is approximately 1 in $220^{17}$.

Of the babies with NTD most were $1^{\text {st }}$ born to the family. This may be explained by the lack of awareness of FA usage pre-conceptionally whereas 
after an affected baby most mothers were aware of the importance of peri-conceptional usage of FA.

More than one third of affected babies were born to mothers from the estate sector. Since the study was carried out only within the hospital and our sample size was small, this may not be the true picture.

More than one third of affected mothers were in social class "V" whereas in the control group only $5 \%$ were from social class "V". Surprisingly none of the affected mothers were from social class "I" or "II". Since none of the affected mothers have used preconceptional FA irrespective of the social class which they are from in our study, we were unable to asses the FA usage in relation to their occupation.

\section{Conclusions}

- Knowledge and awareness of folic acid in relation to the pregnancy was grossly inadequate in the affected group. This was true to a lesser extent in the control group.

- Awareness of folic acid was derived mainly from the family health worker.

- Consanguineous marriages increased the risk of NTDs.

- Risk of recurrence was high when there was a positive family history.

- NTDs were commoner in boys and most were $1^{\text {st }}$ born.

- More than one third of the affected parents were in social class $\mathrm{V}$.

- One third of affected babies were born to mothers from the estate sector.

\section{Recommendations}

- $\quad$ Greater awareness needs to be created among adolescent girls on pre-conceptional FA usage Effective campaigns should be launched using posters and television/radio advertisements, emphasizing the importance of preconceptional FA usage. Health promotion programmes should not only target general population but also health professionals. Another reliable way of promoting FA awareness is giving simple information sheets to general practioners and primary health care services like MOHs and Public Health Workers.

- Promotion of preventive effects of FA on other birth defects

Recent research suggests that FA may prevent other birth defects such as cleft palate and $\operatorname{lip}^{17}$, limb deficiency defects ${ }^{18}$, conotruncal defects $^{19}$, and urinary tract anomalies ${ }^{20}$. Thus, along with the message of prevention of NTD, other benefits of periconceptional FA usage can be emphasized.

- Government and Provincial Councils should fund sustainable health promotion \& education programmes, targeting women of child bearing age and adolescent girls.

Government should fund folate supplementation for pre-conceptional period, so that financially disadvantaged women would not be affected.

- Special attention must be paid to potential mothers in relevant areas.

Both public and health personnel should be able to identify the high risk groups and to advise them to take correct dose of FA at appropriate time.

- Awareness programmes should be launched on proper method of consumption of folate rich foods.

Being a developing country appropriate food preparation advice should be recommended as that is the most inexpensive and practical way of increasing folate level of women in reproductive age.

- $\quad$ Staple food fortification with folic acid.

Full coverage of population can only be achieved by implementing a policy to fortify a staple food with FA. As a developing country, cost in fortifying food is significant, yet should be taken into consideration.

- Establishment of regular surveillance system Surveillance system must be in place islandwide to count the occurrence of cases. The obvious measurement of the impact of the increase folic acid consumption is the reduction of the NTD rate in a population.

\section{Acknowledgments}

The authors wish to thank all the mothers who participated in this study, Dr P.V.R. Kumarasiri, Senior Lecturer, Department of Community Medicine, Faculty of Medicine, Peradeniya, Ethical committee at T.H Kandy, Late $\mathrm{Dr}$ D. Wickramasinghe, Consultant Neurosurgeon, T.H. Kandy, and Dr K. Piyaseeli

\section{References}

1. Myrianthopoulos NC, Melnick M. Studies in neural tube defects. Epidemiologic and etiologic aspects. American Journal of Medical Genetics 1987; 26 (4): 783-96. 
2. Botto LD, Moore CA, Khoury MJ, Erickson JD, Neural tube Defects. New England Journal of Medicine 1999; 341:1509- 19.

3. Lynberg MC, Khoury M, Contribution of birth defects to infant mortality among racial/ethnic minority groups, United States, 1983. Morbidity and Mortality Weekly Report 1990; 39(SS-3): $1-12$.

4. Berry RJ, Li Z, Erickson JD, et al, Prevention of neural tube defects with folic acid in China. China - U.S. Collaborative Project for Neural Tube Defect Prevention. New England Journal of Medicine 1999; 341: 1485.

5. Grimes, DA, Unplanned pregnancies in the United States. Obstetrics and Gynecology 1986; 67: 438.

6. MRC Vitamin study Research Group.Prevention of Neural Tube Defects: Results of the Medical Research Council Vitamin study. Lancet 1991; 338:131-7.

7. Indian Council of Medical Research (ICMR) Collaborating Centers and Central Technical Co-coordinating Unit, ICMR, New Delhi. Multicentric study of efficacy of periconceptional folic acid containing vitamin supplementation in prevention of open neural tube defects from India. Indian Journal of Medicine 2000; 112: 206-11.

8. Czeizel \& Dudas. Prevention of the first occurrence of neural tube defects by periconceptional vitamin supplementation. New England Journal of Medicine 1982; 327(26), 1832-5.

9. Lumley J, Watson L, Watson M and Bower C. Periconceptional supplementation with folate and/or multivitamins for preventing neural tube defects. Cochrane Database Systemic review 2001; 3: CDOO 1056.

10. Missouri department of Health and senior Services Centre for Health Information management and evaluation. Jefferson City, Missouri 65102-0570 (573) 751
11. Chan A, Pickering J, Haan EA, Netting M, Burford A, Johnson A, et al. "Folate before Pregnancy" the impact on women and health professionals of a population based health promotion campaign in South Australia, Medical Journal of Australia 2001; 174, 631-6.

12. Watson M, Watson L, Bell R, and Halliday J. "The increasing knowledge of the role of periconceptional folatein Victorian women of child-bearing age: follow up of a randomized community intervention trial, Australia and New Zealand Journal of Public Health 2001; 25, 38995.

13. Leck, I. Changes in the incidence of neural tube defects. Lancet 1966; 2:791-3.

14. Persad VL, Van Den Hof MC,Dube JM, Zimmer $\mathrm{P}$, incidence of open neural tube acid fortification. Canadian Medical Association Journal. 2002; 167: 241-5.

15. Berry RJ, Li Z, Erickson JD, et al. Preventing neural tube defects with folic acid in China, New England journal of Medicine. 1999; 341: 1485 90.

16. Centers for Disease Control and Prevention: Prevalence of spina bifida at birth- United States, 1983-1990: a comparison of two surveillance systems. 1998; 45(No. SS-2): 15-26.

17. Tolarova M, Harris $\mathrm{J}$ : reduced recurrence of orofacial clefts after periconceptional supplementation with high-dose folic acid and multivitamins. Teratology 1995; 51: 71-8.

18. Yang Q, Khoury MJ, Olney RS, Mulinare J: Does periconceptional multivitamin use reduce the risk for limb deficiency in offspring? Epidemiology 1997; 8: 157 - 61 .

19. Botto LD, Khoury MJ, Mulinare JD: Periconceptional multivitamin use and the occurrence conotruncal heart defects. 1996; 98: $911-7$.

20. Li DK, Daling JR, Mueller BA, Hickok DE, Fantel AG, Weiss NS, Periconceptional multivitamin use in relation to the risk of congenital urinary track anomalies. Epidemiology 1995; 6: $205-7$. 